Article

\title{
Coordination Contracts for Hotels and Online Travel Agents
}

\author{
Qiang Guo ${ }^{1}$, Chris K. Anderson ${ }^{2}$, Junfeng Dong ${ }^{3, * \mathbb{C}}$, Pengfei Zhao ${ }^{4}$ and Qingkai Ji ${ }^{4}$ \\ 1 School of Tourism, Hainan University, Haikou 570228, China; gq@hainanu.edu.cn \\ 2 School of Hotel Administration, Cornell University, Ithaca, NY 14850, USA; cka9@cornell.edu \\ 3 Key Laboratory of Process Optimization and Intelligent Decision-making, Ministry of Education, \\ School of Management, Hefei University of Technology, Hefei 230009, China \\ 4 School of Management, Hainan University, Haikou 570228, China; alx_zhao@hainanu.edu.cn (P.Z.); \\ qingkai.ji@hainanu.edu.cn (Q.J.) \\ * Correspondence: jfdong4@hfut.edu.cn
}

Received: 15 February 2020; Accepted: 15 April 2020; Published: 20 April 2020

\begin{abstract}
Herein, we address a common problem of hotels in the current world of online selling, namely the management of relationships with third party resellers (also known as online travel agents (OTAs)). We highlight the role of OTAs in the current travel landscape, and we discuss the popular contracting forms between OTAs and hotels, which are the so-called merchant and retail (commission) models. We illustrate how these contracts fail to coordinate the hotel-OTA relationship, and then, we develop a new type of contract that can efficiently coordinate a supply chain consisting of the OTA and the individual hotels. We provide theoretical results and numerical examples for a one-to-one model with one OTA and one supplier and a more realistic setting with an OTA selling to consumers on behalf of numerous hotel partners.
\end{abstract}

Keywords: OTA; supply chain coordination; contract

\section{Introduction}

Online travel agents (OTAs) play a critical role in generating demand from potential travelers for hotel companies. One of the obvious benefits of an OTA is the ease with which any consumer can compare prices, research their chosen destinations, and choose the best way to get there, all with a click of a mouse. As they may benefit from the incremental sales generated by the marketing exposure offered by OTAs, hotels are willing to share their inventories with OTAs in exchange for commissions and fees [1-3]. OTAs have been playing a very important role in the hospitality industry for over ten years. Hui et al. [4] analyzed the room rates of 35 hotels in Guangzhou, Shanghai, on four direct and indirect online channels, finding that the local travel agency websites generally offered the lowest rates for upscale and luxury hotels, while the national online travel agency websites offered the overall best rates for mid-priced hotels. Law et al. [5] investigated the practices of five OTA websites and attested that the regional OTA outperformed other global leaders regarding airfares, and a smaller scale OTA offered the lowest-fare air-tickets with the shortest durations. Through an experiment, Anderson [6] illustrated that the hotel reservations on non-OTA channels (call centers, hotel websites, etc.) are impacted by the display or billboard effect created by listing rooms with an OTA. In the experiment, total reservations increased by $7.5 \%-26 \%$ for the four hotels he assessed. In a follow-up piece, Anderson [7] indicated that almost 75\% of consumers who booked rooms on a hotel's website had visited an OTA prior to making the reservation. Ling et al. [8] proposed a new method for hotels to cooperate with an OTA on booking rooms by managing the availability of hotel rooms for the partner OTA. Chan et al. [9] confirmed that OTAs' reviews are important sources of information that influence 
consumer decisions and behavior and further affect the hotel's decisions. Chang et al. [10] researched both the cooperation and competition between OTAs and hotels using the operation flow.

Since OTAs receive substantive commissions from hotel transactions, e.g., Expedia's average commission is 18.8\% (2013 4th quarter report www.expedia.com) and Booking's is 21\% (2013 4th quarter report www.Priceline.com), hotel suppliers often question the value of their models. The focus of our paper is on the hotel-OTA relationship, with the goal of developing a model that better aligns the hotel supplier and OTA. Specifically, we illustrate that the current commission model commonly used to coordinate OTAs and hotels is not Pareto-optimal. We discuss how the current coordination contracts fail to align OTAs and suppliers. Finally, we develop a new contract and illustrate how it can coordinate the supply chain and deliberately allocate profits across suppliers in the case of multiple hotels per market.

The contributions of this paper are three-fold. First, in the supply chain contract coordination area, this paper conducts deeper research to find a contract that can coordinate two channels where one channel's marketing effort can boost the demand for both channels. Although there is prior research on dual-channel coordination contracts and single-channel supply chain coordination contracts with marketing efforts, to the best of our knowledge, these streams have not been integrated. Thus, this research amends this important theoretical gap. Second, to be more applicable in real business, we further extend the model to a multi-hotel OTA setting whereby the OTA allocates its marketing effort (website space or page rank) among these hotels. We prove that our new contract can completely coordinate this N:1 supply chain. Third, this paper is the first research to link hotel revenue management (room allocation) with supply chain coordination (through contracts with OTAs). Furthermore, the demand function in our paper has a general form and can be easily extended to other settings beyond our travel related focus.

To clearly and logically show our findings, we have organized the paper as follows. First, we provide some background and introduce the basic concepts of supply chain coordination. We then proceed to review the related supply chain management and hospitality management literature. We then form the main model and discuss some techniques used in cooperative bargaining. Next, we provide an exhaustive discussion and review of coalition games and applications and highlight techniques and areas for future research.

\section{Literature Review}

Like the prisoner's dilemma, the "double-marginalization effect" is well-known to refer to when there are successive monopolies in a vertical structure, such as manufacturing and retailing (or hotels and OTAs) in a supply chain, where each unit (firm) optimizes their own profits, leading to lower total welfare compared with successive monopolies with vertical integration (see Spengler, [11]; Tirole, [12] for more details).

There may exist a contract that can link each firm in any supply chain. A contract is said to coordinate a supply chain if the supply chain reaches an optimal outcome (e.g., a Nash equilibrium), i.e., no firm has a profitable unilateral deviation from the set of optimal supply chain actions. Ideally, the optimal actions should also be a unique Nash equilibrium, otherwise, the firms may "coordinate" on a suboptimal set of actions [13]. The common coordinating actions are the retailer's order quantity, pricing and the supplier's production [14-18]. As we show in the following current pricing arrangements, the retail commission model (commission contract) or merchant model (wholesale pricing contract) cannot coordinate a hospitality (OTA-hotel) supply chain.

In past related research, using collaboration and coordination in a manufacturing supply chain to solve the double-marginalization effect has been the research focus. Wu et al. [19] researched the effects of sharing demand information with potential entrants and building a marketing channel, and the results revealed that channel construction would increase the barriers to entry for potential entrants and weaken the double-marginalization effect. Mikhail et al. [20] developed a coordination model consisting of a single supplier and $n$ buyers, which utilized a common replenishment time as a 
mechanism to coordinate the supply chain. Contracts with various coordination mechanisms have been widely applied to manufacturing supply chain coordination. These studies have concentrated on a manufacturing supply chain rather than on a services supply chain. The OTA-hotel supply chain exhibits unique characteristics different from the traditional supplier-manufacturer-retailer supply chains often studied in practice. For example, hotel capacity is non-storable and non-transportable [21], and thus allotting guest rooms is always one of the most popular themes in hospitality operations' research areas such as revenue management, although this research is rare in supply chain settings.

To correct the double-marginalization effect, some popular types of contracts have been studied. Pasternack [22] proposed a buy-back contract to coordinate a fixed-price newsvendor. In that contract, the supplier charges a wholesale price per unit and pays the retailer a buy-back price per unit of leftover inventory. Dana and Spier [23] applied buy-back contracts in a single supplier-multiple retailer setting with perfect competition. Flexible quantity contracts were originally studied by Tsay and Lovejoy [24]. Moreover, Shi et al. [25] studied a joint ordering and pricing problem for a retailer whose supplier provides an all-unit quantity discount for the product. In these contracts, the retailer buys goods at a wholesale price but can partly return the leftover inventory for a full refund at the end of the sales season. In sales rebate contracts, the supplier gives the retailer a rebate per unit sold above a fixed threshold. In the revenue sharing contracts studied by Cachon [13], the retailer agrees to share part of the revenues with the supplier in return for a lower wholesale price. All these contracts can coordinate a newsvendor supply chain and arbitrarily allocate profits. In other words, the whole supply chain's optimal profits can be allocated at shares from 0 to 1 according to each side's negotiation abilities. For more details, see Cachon [13], Zhao et al. [26], and Xu et al. [27] for a review of supply chain coordination from various perspectives.

Unfortunately, all these aforementioned types of contracts between suppliers and retailers fail to work in the hospitality supply chain studied here. Unlike in the manufacturing supply chain where the retailer should keep goods in their local store before the sales period, hotel capacity is non-storable and non-transportable, and thus there is no need for an OTA to order in advance. Under this setting, buy-back and quantity flexibility contracts fail to work. Although revenue sharing contracts may be theoretically feasible in a hospitality management setting, they fail in practice. In the following, we discuss why these existing contracts cannot be used to coordinate the OTA-hotel supply chain.

An OTA provides a prominent display/position on their website for a particular hotel, which can be seen as a type of marketing effort. Cachon [13] has shown that revenue sharing contracts cannot coordinate a supplier-retailer chain when the cost function of the marketing effort can only be observed by the retailer and as a result cannot be written into the contract. Tsao and Sheen [28] also deem promotion cost sharing as a critical mechanism to coordinate a supply chain. A coordinated marketing effort is possible only if the supplier assumes part of the effort costs, but then the retailer has every reason to misrepresent the true costs. For the same reason, sales rebate contracts and quantity discount contracts also fail to coordinate supply chains without full information sharing. In the newsvendor setting, Taylor [29] showed that the combinations of a sales rebate contract with a buy-back contract can coordinate the marketing effort in a supply chain. The sales rebate contract gives the retailer too much incentive to exert effort, but the buy-back contract reduces the retailer's incentive, thereby providing the needed balance. However, this contract requires four parameters, which makes it far too complex for a contract. In our specific setting, the marketing efforts of the OTA (display position) on their website can be seen by everyone, including the hotel. The marketing effort data can be collected through a within-subjects and between-groups design using eye-tracking technology, such as in Scott et al. [30], Jurado et al. [31], and Leiva et al. [32]. We assume that the cost (here, it is an opportunity cost, i.e., the prominent position not allocated to another hotel provider) of the marketing effort cannot be seen by others (hotel partners), and thus cannot be written in any contract. Cachon [13] used a specific type of quantity discount contract to coordinate a supplier-retailer chain with a marketing effort, but it cannot be used in a dual-channel setting, as in our scenario. A retailer's additional service in the dual-channel manufacturing supply chain problem has also recently received 
attention, such as in Yan and Pei [33], Dan et al. [34], Routroy et al. [35], and others [36,37]. In addition to not providing a coordination mechanism, these papers suppose that retail services will boost the demand of the retailer and lessen the demand of the manufacture, whereas in our setting, the retail marketing effort will bring new demand for both channels since the OTA is only compensated as a result of a hotel partner transaction.

The revenue sharing contract can only solve the problem of one supplier and one (or several) retailer(s) with the supplier not having their own revenue stream. However, here, we actually consider two revenue streams in the hospitality supply chain: one is from the OTA, and another is from the hotel itself (it has been defined as a dual-channel supply chain in some literatures). To coordinate this dual-channel supply chain, the revenue information from the supplier's own channel should be considered in the contract, which means that the quantity discount contract discussed in Cachon [13] will not work. In fact, to make revenue sharing contracts work reasonably well, the hotel needs to share its own channel revenue with the OTA and not vice versa, like in the traditional revenue sharing contract (as shown later in Theorem 1). Chen et al. [38] used a profit sharing contract to coordinate a dual-channel supply chain where the manufacture shares his own channel revenue with the supplier. Cai et al. [39] proposed an improved contract based on revenue sharing that allows members to share profits and implement alternative contracts to coordinate a vendor-managed inventory supply chain with service-level sensitive customers. Zhao [40] explored collusion and information sharing in a supply chain consisting of two downstream retailers and a mutual upstream manufacturer with the coordination by a revenue sharing contract. In practice, similar to the marketing effort opportunity cost, it would be difficult for the OTA to verify the hotels' own channel revenues, which will create an additional information cost for the whole system.

Some existing literature utilized a combination of a revenue sharing contact and a pricing scheme to coordinate a dual-channel supply chain [41-44]. The contract is complex to apply and further requires the retailer and firm to have different selling prices. One of the complexities of the OTA-hotel supply chain is caused by so called rate parity. Rate parity is the industry practice whereby the prices for a hotel room at a given hotel on a stay date are the same regardless of where the consumer shops for those prices, i.e., the same price exists at Expedia.com and at Hilton.com. Due to rate parity, selling price flexibility is removed from contracts. Rate parity further restricts the use of the minimum retail price-constrained revenue sharing contract of Ryan et al. [45].

The existing hospitality supply chain management literature also fails to solve the coordination problem in a dual-channel supply chain with a marketing effort. Guo and He [46] set up a contract to coordinate a hotel and a tour operator that provides two types of tour packages, luxury and economy, but they did not incorporate the room capacity allotment as a decision, as in a dual-channel supply chain. Hua et al. [47] studied how a hotel with dual-channel (one an OTA) can optimize its profits through room allotment decisions, but coordination was not studied. Guo et al. [48] studied the optimal commission strategy for hotels when they cooperate with an OTA website that can use its marketing effort to affect demand. Ling et al. [49] made a further study of an examination of hotel pricing and travel agencies' online distribution of rooms, but the above papers did not discuss coordination. Yang and Leung [50] investigated various factors behind price discounts (as a type of price disparity), aiming to better understand hotels' cross-channel pricing mechanisms. We summarize the main literature in Table 1 and illustrate where our paper sits within this body of knowledge. 
Table 1. Literature summary.

\begin{tabular}{|c|c|c|c|c|c|}
\hline & Dual Channel & Rate Parity & $\begin{array}{l}\text { Capability } \\
\text { Allocation }\end{array}$ & $\begin{array}{l}\text { Marketing Effort } \\
\text { (Cost as Private } \\
\text { Information) }\end{array}$ & Coordination \\
\hline Hua et al. [47] & $\sqrt{ }$ & & $\sqrt{ }$ & & \\
\hline Cachon [13] & & & $\sqrt{ }$ & $\sqrt{ }$ & $\sqrt{ }$ \\
\hline Cai [41] & $\sqrt{ }$ & & $\sqrt{ }$ & & $\sqrt{ }$ \\
\hline Guo and He [46] & $\sqrt{ }$ & & $\sqrt{ }$ & & $\sqrt{ }$ \\
\hline Guo et al. [48] & $\sqrt{ }$ & $\sqrt{ }$ & $\sqrt{ }$ & & \\
\hline Yan and Pei [33] & $\sqrt{ }$ & & & Retail service & \\
\hline Dan et al. [34] & $\sqrt{ }$ & & & Retail service & \\
\hline Chen et al. [38] & $\sqrt{ }$ & & & & $\begin{array}{l}\sqrt{ } \text { (transfer } \\
\text { manufacturer's } \\
\text { own channel } \\
\text { profit to } \\
\text { retailer) }\end{array}$ \\
\hline Ryan et al. [45] & $\sqrt{ }$ & & & & $\sqrt{ }$ \\
\hline Yang and Leung [50] & $\sqrt{ }$ & & $\sqrt{ }$ & Market power & \\
\hline Ling et al. [8] & $\sqrt{ }$ & $\sqrt{ }$ & $\sqrt{ }$ & & \\
\hline Chang et al. [10] & $\sqrt{ }$ & $\sqrt{ }$ & $\sqrt{ }$ & Website service quality & \\
\hline Ling et al. [49] & $\sqrt{ }$ & $\sqrt{ }$ & $\sqrt{ }$ & & \\
\hline Chan et al. [9] & $\sqrt{ }$ & $\sqrt{ }$ & & online review & \\
\hline Our paper & $\sqrt{ }$ & $\sqrt{ }$ & $\sqrt{ }$ & $\sqrt{ }$ & $\sqrt{ }$ \\
\hline
\end{tabular}

\section{Model}

We consider two scenarios where the firms are risk neutral and the fixed costs of hotels and the OTA will not be considered, which simplifies the work and does not result in the loss of generality. In the first setting, there is only one hotel and one OTA in our hospitality chain. The hotel sells its rooms through the OTA and its own channels, which may include its front desk, hotel website, or call center. The hotel will pay the OTA commissions at a rate (r) for each room sold through the OTA's channel, which means that the OTA has to pay a wholesale price $(w)$ for each room, where $w=(1-r) P$. The OTA can invest in a marketing effort such as its website's home page space priority (i.e., provide better placement for the hotel) or advertising to positively influence the demand rate of each channel for the hotel. As the wholesale price is less than the front desk price, the hotel always sets an upper bound to limit the number of rooms that an OTA can sell. Following the existing practice of rate parity, we assume that the OTA's online price to consumers and the hotel's front desk price are equal because of the high transparency of the online sales price. In the second scenario, the OTA will work with multiple hotels and should allot its marketing effort across the hotels.

\subsection{Notation and Assumptions}

$Q:$ The total number of hotel rooms that can be sold

$w$ : Wholesale price (that the OTA pays the hotel for each room sold)

$P$ : Hotel retail price and OTA retail price

$c_{H}:$ Costs for the hotel per room sold

$c_{I}$ : Costs for the OTA per room sold

$q$ : Upper bound of the rooms allocated to the OTA

$q_{H}=Q-q$ : Expected upper limit of the number of rooms that the hotel can sell through its own channels

$e$ : Marketing effort of the OTA

M: Marketing budget of the OTA (only used in the N:1 setting)

The cost of the OTA's marketing effort are $g(e)$. We assume $\frac{\partial g}{\partial e}>0$ and $\frac{\partial^{2} g}{\partial e^{2}}>0$, which means that due to the law of diminishing marginal returns, the cost will rise faster than the marketing effort. In addition, the demand distribution and all parameters except for the marketing effort cost function $g(e)$ are commonly known. This is a perfect information benchmark, which means that we cannot rely 
on asymmetric information or irrational behavior to get our result. We can also loosen this condition for further research.

The probability density function faced by the OTA $f(y \mid e)$ is independent from $q$; thus the demand distribution function faced by the OTA will be $F(y \mid e)=\int_{0}^{y} f(y \mid e) d y$.

Therefore, the expected customer volume of the OTA is as follows:

$$
\begin{aligned}
& S_{I}(q, e)=E \min (q, y)=q(1-F(q \mid e))+\int_{0}^{q} y f(y \mid e) d y \\
= & q(1-F(q \mid e))+q F(q \mid e)-\int_{0}^{q} F(y \mid e) d y=q-\int_{0}^{q} F(y \mid e) d y
\end{aligned}
$$

The probability density function faced by hotel $g(x \mid e)$ is independent of $q$; thus, the demand distribution function faced by the hotel is as follows: $\mathrm{G}(x \mid e)=\int_{0}^{x} g(x \mid e) d x$.

Therefore, the expected customer volume of the hotel is as follows:

$$
S_{H}\left(q_{H}\right)=q_{H}-\int_{0}^{q_{H}} G(x \mid e) d x
$$

The expected profit of the whole system considering the cost of the marketing effort is

$$
\Pi=\left(\mathrm{P}-c_{I}-c_{H}\right) S_{I}+\left(P-c_{H}\right) S_{H}-g
$$

where $0<\mathrm{c}_{H}<w<\mathrm{P}$ (which ensures that all firms have positive profits; otherwise, they will no longer participate). In addition, $\mathrm{P}, Q, c_{I}$, and $c_{H}$ are exogenous. Furthermore, $e$ is set by the OTA and $w, q$ are set by the hotel, and so they are endogenous. Hotels have no market power; thus, the retail price is exogenous and set by the hotel market, which is consistent with other approaches, for example, Pasternack [18] is consistent with our focus on the contract itself versus the optimal prices across a set of multiple hotels.

We can show that the Hessian matrix of the second derivative with respect to $q^{*}$ and $e^{*}$ of the total profits of the system is positive definite. Therefore, we can use the first order condition to get the optimal decisions.

\subsection{One-to-One Model with One OTA and One Hotel}

Our game proceeds as follows. First, the terms of the contract are specified. Then, the hotel chooses the upper bound of the number of rooms $(q)$ to allocate to the OTA for sale and sets the wholesale price $(w)$, and the OTA chooses their marketing effort level (e).

First, we prove that under the current practice, regardless of whether a commission model or merchant model is used, there exists a double-marginalization effect in this hospitality supply chain.

As a benchmark, we assume that the whole hospitality supply chain is under control of one central decision maker, who is willing to maximize the profit of the total hospitality supply chain. The mathematical model of this problem is

$$
\max \prod_{e, q}=\left(\mathrm{P}-\mathrm{c}_{\mathrm{I}}-\mathrm{c}_{\mathrm{H}}\right) \mathrm{S}_{\mathrm{I}}+\left(\mathrm{P}-\mathrm{c}_{\mathrm{H}}\right) \mathrm{S}_{\mathrm{H}}-\mathrm{g}
$$

The Hessian matrix of the second derivative with respect to $q$ and $e$, is positive definite and $\Pi^{\prime \prime}(\mathrm{e})=\left(\mathrm{P}-\mathrm{c}_{\mathrm{I}}-\mathrm{c}_{\mathrm{H}}\right) \mathrm{S}_{\mathrm{I}}{ }^{\prime \prime}(\mathrm{e})+\left(\mathrm{P}-\mathrm{c}_{\mathrm{H}}\right) \mathrm{S}_{\mathrm{H}^{\prime \prime}}(\mathrm{e})-\mathrm{g}^{\prime \prime}(\mathrm{e})<0$, we can use the first order condition to get the optimal $e^{o}$.

The first order condition for $e$ is

$$
\frac{\partial \Pi}{\partial e}=\left(\mathrm{P}-c_{I}-c_{H}\right) \frac{\partial \mathrm{S}_{I}}{\partial \mathrm{e}}+\left(P-c_{H}\right) \frac{\partial \mathrm{S}_{H}}{\partial \mathrm{e}}-\frac{\partial \mathrm{C}}{\partial e}
$$


The first order condition for $q$ is

$$
\frac{\partial \Pi}{\partial q}=\left(\mathrm{P}-c_{H}-c_{I}\right) \frac{\partial S_{I}}{\partial q}+\left(P-c_{H}\right) \frac{\partial S_{H}}{\partial q}
$$

Thus,

$$
\frac{\mathrm{g}^{\prime}\left(\mathrm{e}^{\mathrm{o}}\right)}{\mathrm{S}_{\mathrm{I}}{ }^{\prime}\left(\mathrm{e}^{\mathrm{o}}\right)}=\left(\mathrm{P}-\mathrm{c}_{\mathrm{I}}-\mathrm{c}_{\mathrm{H}}\right)+\left(\mathrm{P}-\mathrm{c}_{\mathrm{H}}\right) \frac{\mathrm{S}_{\mathrm{H}^{\prime}}\left(\mathrm{e}^{\mathrm{o}}\right)}{\mathrm{S}_{\mathrm{I}^{\prime}}\left(\mathrm{e}^{\mathrm{o}}\right)}
$$

Here, $e^{o}$ is the optimal marketing effort for the whole hospitality supply chain.

However, in reality, the marketing effort is actually decided by the OTA. The problem faced by him in the wholesale model is

$$
\max \prod_{e}=\left(\mathrm{P}-\mathrm{c}_{\mathrm{I}}-\mathrm{w}\right) \mathrm{S}_{\mathrm{I}}-\mathrm{g}
$$

The first order condition for $e$ is

$$
\frac{\mathrm{g}^{\prime}\left(\mathrm{e}^{1 *}\right)}{\mathrm{S}_{\mathrm{I}}{ }^{\prime}\left(\mathrm{e}^{1 *}\right)}=\mathrm{P}-\mathrm{c}_{\mathrm{I}}-\mathrm{w}
$$

Here, $e^{1 *}$ is the optimal marketing effort for the OTA in the wholesale model.

Comparing Conditions (2) and (4) and consisting $\mathrm{S}_{\mathrm{I}} \geq 0, \mathrm{~S}_{\mathrm{H}} \geq 0, \mathrm{P}-\mathrm{c}_{\mathrm{H}}>0$ and $\mathrm{w} \geq \mathrm{c}_{\mathrm{H}}$ (otherwise, the hotel will not be willingness to sell rooms through the OTA), we get

$$
\frac{g^{\prime}\left(e^{o}\right)}{S_{I^{\prime}}\left(e^{o}\right)}>\frac{g^{\prime}\left(e^{1 *}\right)}{S_{I^{\prime}}\left(e^{1 *}\right)}
$$

From $g^{\prime}(\mathrm{e})>0$ and $S_{I}^{\prime \prime}(\mathrm{e})<0$, we can get

$$
\left[\frac{g^{\prime}}{S_{I}^{\prime}}\right]^{\prime}=\frac{g^{\prime \prime} S_{I}{ }^{\prime}-g^{\prime} S_{I^{\prime \prime}}}{\left[S_{I^{\prime}}\right]^{2}}>0
$$

Thus $e^{o}>e^{1 *}$. That is, the OTA's optimal marketing effort in the wholesale model will be lower than its first-best decision.

The result for the commission model is similar. Assume that $m$ is the commission, and thus the OTA's optimal marketing decision problem is

$$
\max \prod_{e}=\left(m-c_{I}\right) S_{I}-g
$$

The first order condition for $e$ is

$$
\frac{g^{\prime}\left(e^{2 *}\right)}{S_{I^{\prime}}\left(e^{2 *}\right)}=m-c_{I}
$$

Here, $e^{2 *}$ represents the optimal marketing effort for the OTA in the commission model.

Comparing Conditions (2) and (6) and considering $m<P-\mathrm{c}_{\mathrm{H}}$, we can get

$$
\frac{g^{\prime}\left(e^{o}\right)}{S_{I^{\prime}}\left(e^{o}\right)}>\frac{g^{\prime}\left(e^{2 *}\right)}{S_{I^{\prime}}\left(e^{2 *}\right)}
$$

Thus, $e^{0}>e^{2 *}$. That is, the OTA's optimal marketing effort in the commission model will be lower than its first-best decision.

We can also use a similar method to prove another optimal decision variable, that is, the upper bound of the number of rooms $q^{*}$ that the hotel sets for the OTA to sell is not equal to the best-first benchmark $q^{\mathrm{o}}$. 
As a result, we need a new type of contract to coordinate this hospitality supply chain. To illustrate our logic, we provide a pilot contract before the main contract.

Theorem 1. The following reverse profit sharing contract can coordinate the hospitality supply chain of one hotel and one OTA who can use their priority to order the hotel's name on their website to influence customer volumes.

$$
\begin{gathered}
\Pi_{\mathrm{I}}=\phi\left(\mathrm{P}-\mathrm{c}_{\mathrm{H}}\right) \mathrm{S}_{\mathrm{H}}+\left(\mathrm{P}-\mathrm{c}_{\mathrm{I}}-\mathrm{w}\right) \mathrm{S}_{\mathrm{I}}-\mathrm{g} \\
\Pi_{\mathrm{H}}=\quad(1-\phi)\left(\mathrm{P}-\mathrm{c}_{\mathrm{H}}\right) \mathrm{S}_{\mathrm{H}}+\left(\mathrm{w}-\mathrm{c}_{\mathrm{H}}\right) \mathrm{S}_{\mathrm{I}}
\end{gathered}
$$

where

$$
\mathrm{w}=(1-\phi)\left(\mathrm{P}-\mathrm{c}_{\mathrm{I}}-\frac{\mathrm{g}}{\mathrm{S}_{\mathrm{I}}}\right)+\phi \mathrm{c}_{\mathrm{H}}
$$

As both the OTA and the hotel share a part of the whole supply chain profits, they will behave like they are the only decision maker in this system. In addition, because $\varnothing \in[0,1]$, the profits can be arbitrarily split. For this pilot contract to work properly, we need an additional assumption that the costs of the marketing effort of the OTA can be justified so it can be written into the contact through the $w$.

Unfortunately, this assumption does not always stand. Actually, most contract literature assume that the costs of the marketing effort cannot be justified due to retailers being unwilling to share information with suppliers. In addition, although Cachon [13] assumes that retail revenues can be transferred to the supplier based on the fact that the supplier knows the exact volume the retailer has sold, it is hard to believe that the hotel can share the revenues from its own sales channel with the retailer. To abandon these additional assumptions, we give our main contract as follows.

Theorem 2. The following incentive shifting contract $(a, b)$ can coordinate a hospitality supply chain with one hotel and one OTA who can use her marketing effort to influence customer volumes.

$$
\begin{gathered}
\Pi_{I}=\left(P-c_{I}-w\right) S_{I}-g-a q^{2}+b e^{2} \\
\Pi_{H}=\left(P-c_{H}\right) S_{H}+\left(w-c_{H}\right) S_{I}+a q^{2}-b e^{2} \\
\mathrm{a}=\frac{\left(c_{H}-w\right)}{2 q} \frac{\partial S_{I}}{\partial q}-\frac{\left(P-c_{H}\right)}{2 q} \frac{\partial S_{H}}{\partial q} \mid e^{o}, q^{o} \\
\mathrm{~b}=\frac{\left(w-c_{H}\right)}{2 e} \frac{\partial S_{I}}{\partial e}+\frac{\left(P-c_{H}\right)}{2 e} \frac{\partial S_{H}}{\partial e} \mid e^{o}, q^{o}
\end{gathered}
$$

In this contract, $e$ is the marketing effort of the OTA, which can be identified by applying eye-tracking technology to the advertisements of the OTA. The method is always used by behavioral economics (Jurado, [31], Katerina and Nicolaos, [51], etc.). As is clear, $e$ can be justified and written into the contract that will be exerted, where $a$ and $b$ are the contract parameters dependent on the wholesale price $(w)$ (set by the hotel). As there is no $g(e)$ in it, this contract does not need the marketing effort cost information of the OTA, and this follows the mainstream literature's assumption. The hotel will maximize their profits by increasing the $w$ on the condition that the OTA will agree to adopt this new contract. If the $w$ is too high (or too low) such that the profits of the OTA (hotel) are lower than those in the commission model (commission contract) or merchant model (wholesale pricing contract), either the OTA or the hotel will prefer the old contract. As such, there will be a participation interval for the $w$. The exact number of the $w$ in the interval is dependent on each side's bargaining power. Here, we define the OTA's bargaining power as

$$
\varphi_{O}=\frac{\Pi_{I}}{\Pi_{I}+\Pi_{H 2}}=\frac{\left(P-c_{I}-w\right) S_{I}-g-a q^{2}+b e^{2}}{\left(P-c_{I}-c_{H}\right) S_{I}-g}
$$


while the hotel's bargaining power is

$$
\varphi_{H}=1-\varphi_{O}=\frac{\Pi_{H 2}}{\Pi_{I}+\Pi_{H 2}}
$$

Here,

$$
\Pi_{\mathrm{H} 2}=\left(\mathrm{w}-c_{H}\right) S_{I}+a q^{2}-b e^{2}
$$

Thus,

$$
\mathrm{w}=\frac{\varphi_{o}\left(\Pi-\left(P-c_{H}\right) S_{H}\right)-\left(P-c_{I}\right) S_{I}+g+\frac{q}{2}\left(c_{H} \frac{\partial S_{I}}{\partial q}-\left(P-c_{H}\right) \frac{\partial S_{H}}{\partial q}\right)-\frac{e}{2}\left(\left(P-c_{H}\right) \frac{\partial S_{H}}{\partial e}-c_{H} \frac{\partial S_{I}}{\partial e}\right)}{\frac{q}{2} \frac{\partial S_{I}}{\partial q}+\frac{e}{2} \frac{\partial S_{I}}{\partial e}-S_{I}} \mid e^{o}, q^{o}
$$

Therefore, the commissions can be seen as a direct tradeoff of the negotiation powers of the hotel and the OTA.

By using this contract, once the $w$ is set by the hotel according to each side's negotiation power, $a(w)$ and $b(w)$ will be automatically and simultaneously set. Then, the hotel will choose the $q$ and the OTA will choose the $e$. Actually, because this contract can arbitrarily allocate the profits between the OTA and hotel, we show that there is no difference in the preferences of the OTA or the hotel regarding contract parameters $(w, a, b)$.

Proof. Substitute the $\mathrm{w}, \mathrm{a}, \mathrm{b}$ into $\Pi_{\mathrm{I}}, \Pi_{\mathrm{H}}$, and deduce the first order condition of the $e$ and $q$, respectively, we can find

$$
\begin{gathered}
\frac{\partial \Pi_{I}}{\partial e}-\frac{\partial \Pi}{\partial e}=\left(w-c_{H}\right)\left(\left.\frac{\partial S_{I}}{\partial e}\right|_{e^{0}, q^{0}}-\frac{\partial S_{I}}{\partial e}\right)+\left(P-c_{H}\right)\left(\left.\frac{\partial S_{H}}{\partial e}\right|_{e^{0}, q^{0}}-\frac{\partial S_{H}}{\partial e}\right) \\
\frac{\partial \Pi_{H}}{\partial q}-\frac{\partial \Pi}{\partial q}=\left(P-c_{I}-w\right)\left(\frac{\partial S_{I}}{\partial q}-\frac{\partial S_{I}}{\partial q} \mid e^{0}, q^{0}\right)
\end{gathered}
$$

which means

$$
\begin{aligned}
& \frac{\partial \Pi_{\mathrm{I}}}{\partial e}-\frac{\partial \Pi}{\partial e}=\frac{\partial \Pi}{\partial e}=\frac{\partial \Pi_{\mathrm{I}}}{\partial e}=\frac{\partial \Pi_{\mathrm{H}}}{\partial e}=\left.0\right|_{e^{0}, q^{0}} \\
& \frac{\partial \Pi_{\mathrm{H}}}{\partial q}-\frac{\partial \Pi}{\partial q}=\frac{\partial \Pi}{\partial q}=\frac{\partial \Pi_{\mathrm{H}}}{\partial q}=\frac{\partial \Pi_{\mathrm{I}}}{\partial q}=\left.0\right|_{e^{0}, q^{0}}
\end{aligned}
$$

Thus, the OTA and the hotel will rationally set their respective optimal decisions $e^{*}$ and $q^{*}$ equal to the first-best decision pair $e^{0}, q^{0}$ in a centralized system (incentive compatibility constraint). Furthermore, because this contract can arbitrarily allocate the profits, there is no difference regardless of which side offers this contract. This is referred to as a perfectly coordinated supply chain.

As a numerical example, suppose that one hotel with a $Q=200$ rooms and one OTA face independent randomly normally distributed customer streams. Therefore, the expected customer volume of the OTA is

$$
S_{I}(q, e)=q-\int_{0}^{q} \frac{1}{2}\left[1+\operatorname{erf}\left(\frac{y-u_{I}}{\sigma_{I} \sqrt{2}}\right)\right] d y
$$

and the expected customer volume of the hotel is

$$
S_{H}(q, e)=(Q-q)-\int_{0}^{Q-q} \frac{1}{2}\left[1+\operatorname{erf}\left(\frac{z-u_{H}}{\sigma_{H} \sqrt{2}}\right)\right] d z
$$

We further assume that

$$
\mu_{\mathrm{I}}=100+10 e, \sigma_{\mathrm{I}}=100, \mu_{\mathrm{H}}=150+5 e, \sigma_{\mathrm{H}}=150, \text { and } P=200 .
$$

The hotel should pay the variable costs for each room sold of $c_{H}=50$ including housekeeping and other requirements for providing the service. Similarly, the OTA pays the variable costs for each room sold of $c_{I}=10$ including transaction fees (credit card fees, etc.). The OTA has a cost function $\mathrm{g}(\mathrm{e})=10 \times \mathrm{e}^{2}$ for each unit of marketing effort. 
If this hospitality supply chain was under control by one decision-maker, the first-best decision would be $q^{0}=117.05$ and $e^{\mathrm{o}}=12.82$, and then the profit of the whole system would be $\Pi^{\circ}=24709.6$. If using the simple wholesale model, the optimal decisions of the hotel and the OTA would be $q^{*}=98.81, e^{*}=2.95$, and $w^{*}=182.9$. Then, the profit of the OTA would be $\Pi_{I}^{*}=459.45$, the profit of the hotel would be $\Pi_{H}^{*}=21,957.6$, and the total profit of this system would be $\Pi^{*}=22417$.

If the hotel and the OTA use an incentive shifting contract, they will receive continuously changeable profits based on the comparative size of their respective negotiation power. The total profit remains as the first-best condition. In addition, if $\varphi_{o} \in(0.034,0.198)$ with $w \in(137.41,180.97)$, each side will benefit from this contract compared with a simple commission contract. Table 2 summarizes the OTA and supplier profits for a series of parameter values. As seen in Table 2, we can find that the wholesale price $(w)$, the contract parameter $b$ and the hotel's profits $\left(\Pi_{H}\right)$ decrease as the OTA's bargaining power $\left(\varphi_{0}\right)$ increases. In contrast, when the OTA's bargaining power $\left(\varphi_{0}\right)$ increases, the contract parameter $a$ and the OTA's profits $\left(\Pi_{I}\right)$ will increase as well.

Table 2. Numerical Example-OTA and a single supplier.

\begin{tabular}{ccccccc}
\hline $\boldsymbol{w}$ & $\boldsymbol{a}$ & $\boldsymbol{b}$ & $\boldsymbol{\varphi}_{\boldsymbol{o}}$ & $\boldsymbol{\Pi}_{\boldsymbol{I}}$ & $\boldsymbol{\Pi}_{\boldsymbol{H} \mathbf{2}}$ & $\boldsymbol{\Pi}_{\boldsymbol{H}}$ \\
\hline 190 & 0 & 10 & 0 & 0 & $13,858.5$ & $24,709.6$ \\
181.23 & 0.032 & 9.58 & 0.033 & 457.33 & $13,401.1$ & $24,252.5$ \\
180.97 & 0.033 & 9.57 & 0.034 & 471.19 & $13,387.3$ & $24,238.4$ \\
163.439 & 0.1 & 8.74 & 0.1 & 1385.85 & $12,472.6$ & $23,323.8$ \\
137.413 & 0.195 & 7.498 & 0.198 & 2743.98 & $11,114.5$ & $21,965.6$ \\
137.147 & 0.196 & 7.486 & 0.199 & 2757.84 & $11,100.6$ & $21,951.8$ \\
83.765 & 0.393 & 4.947 & 0.4 & 5543.39 & 8315.08 & $19,166.2$ \\
30.6494 & 0.59 & 2.421 & 0.6 & 8315.08 & 5543.39 & $16,394.5$ \\
0 & 0.704 & 0.963 & 0.7154 & 9914.42 & 3944.05 & $14,795.2$ \\
-22.47 & 0.787 & -0.105 & 0.8 & $11,086.3$ & 2771.69 & $1,3622.8$ \\
-75.58 & 0.983 & -2.63 & 1 & $13,858.5$ & 0 & $10,851.1$ \\
\hline
\end{tabular}

\subsection{OTA and Multiple Hotels}

To be more realistic, we extend our setting to one where $N$ hotels want to cooperate with the OTA. Since we are assuming exogenous prices, to ease the presentation, we assume that the hotels compete for business on the OTA but their hotel-specific demand functions are not a function of the actions of other hotels. Therefore, they are not competitors when using their own sale channels, but they are still competing for customers on the OTA. All these hotels are simultaneously willing to set contracts with the OTA, and the OTA should allot their marketing effort among these hotels according to their marketing budget $(M)$.

If using the simple commission contract, the model of this management problem would be

$$
\begin{gathered}
\max _{e_{i}^{*}} \pi_{I}=\sum_{i=1}^{N}\left(P_{i}-w_{i}-c_{I i}\right) S_{I i}-M \\
\text { s.t. } \sum_{i=1}^{N} \mathrm{~g}_{i}\left(e_{i}\right)=M \\
\underset{q_{q^{*}, m_{i}^{*}}^{*}}{\max _{H i}=}\left(P_{i}-c_{H i}\right) S_{H i}+\left(w_{i}-c_{H i}\right) S_{I i} \\
i=1,2,3 \ldots N
\end{gathered}
$$

The first order condition to $q_{i}$ is

$$
\frac{\partial \pi_{H i}}{\partial q_{i}}=\left(P_{i}-c_{H i}\right) \frac{\partial S_{H i}}{\partial q_{i}}+\left(w_{i}-c_{H i}\right) \frac{\partial S_{I i}}{\partial q_{i}}
$$


If the whole supply chain was under the control of one decision maker, the model would be

$$
\begin{gathered}
\pi=\sum_{i=1}^{N}\left(P_{i}-c_{H i}\right) S_{H i}+\left(P_{i}-c_{I i}-c_{H i}\right) S_{I i}-M \\
\text { s.t. } \sum_{i=1}^{N} \mathrm{~g}_{i}\left(e_{i}\right)=M \\
i=1,2,3 \ldots N
\end{gathered}
$$

First order condition for $q_{i}$ is

$$
\frac{\partial \pi}{\partial q_{i}}=\left(P_{i}-c_{H i}\right) \frac{\partial S_{H i}}{\partial q_{i}}+\left(P_{i}-c_{I i}-c_{H i}\right) \frac{\partial S_{I i}}{\partial q_{i}}
$$

To get the first order condition for the $e$, we use the Lagrange multiplier method due to the constraint condition.

$$
\begin{gathered}
\mathrm{L}_{\pi}=\sum_{i=1}^{N} \Gamma_{i}+\lambda\left(\sum_{i=1}^{N} g_{i}\left(e_{i}\right)-M\right) \\
\frac{\partial \mathrm{L}_{\pi}}{\partial e_{i}}=\frac{\partial \Gamma_{i}}{\partial e_{i}}+\lambda \frac{\partial g_{i}}{\partial e_{i}}=0
\end{gathered}
$$

By solving Conditions (18) and (19), we can get the optimal decision pair $\left(e_{i}^{o}, q_{i}^{o}\right)$.

Compare Conditions (17) and (18) because $P_{i}>w_{i}+c_{I i}, \frac{\partial \pi_{H i}}{\partial q_{i}}<\frac{\partial \pi}{\partial q_{i}}$.

In addition, because $\pi_{H i}^{\prime \prime}\left(q_{i}\right) \leq 0, \Pi^{\prime \prime}\left(q_{i}\right) \leq 0$, we can get $q_{i}^{w^{*}}<q_{i}^{o}$. That is to say, the commission contract cannot coordinate the hospitality supply chain.

In fact, the incentive shifting contract can coordinate the hospitality supply chain in this setting, too.

Theorem 3. The following incentive shifting contract $(\boldsymbol{a}, \boldsymbol{b})$ can coordinate the hospitality supply chain with one OTA and multiple hotels.

$$
\begin{aligned}
& \pi_{\mathrm{I}}=\sum_{i=1}^{N}\left(P_{i}-c_{I i}-w_{i}\right) S_{I i}-a_{i} q_{i}^{2}+b_{i} e_{i}^{2}-M \\
& \Pi_{H i}=\left(P_{i}-c_{H i}\right) S_{H i}+\left(w_{i}-c_{H i}\right) S_{I i}+a_{i} q_{i}^{2}-b_{i} e_{i}^{2} \\
& \text { s.t. } \sum_{i=1}^{N} \mathrm{~g}_{i}\left(e_{i}\right)=M \\
& a_{i}=\frac{\left(P_{i}-c_{I i}-w_{i}\right)}{2 q_{i}} \frac{\partial S_{I i}}{\partial q_{i}} \mid e_{i}=e_{i}{ }^{o}, q_{i}=q_{i}{ }^{o} \\
& b_{i}=\frac{\left(P_{i}-c_{H i}\right)}{2 e_{i}} \frac{\partial S_{H i}}{\partial e_{i}}+\frac{\left(w_{i}-c_{H i}\right)}{2 e_{i}} \frac{\partial S_{I i}}{\partial e_{i}} \mid e_{i}=e_{i}{ }^{o}, q_{i}=q_{i}^{o}
\end{aligned}
$$

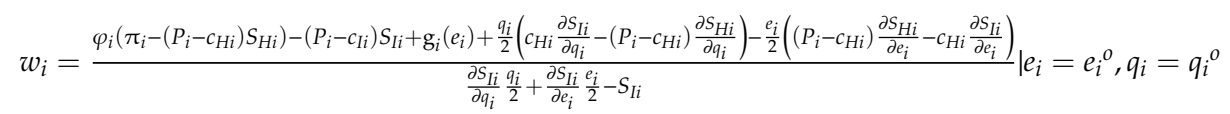

where

$$
\begin{gathered}
\varphi_{i}=\frac{\pi_{I i}}{\pi_{I i}+\pi_{H i 2}}=\frac{\left(P_{i}-c_{I i}-w_{i}\right) S_{I i}-g_{i}-a_{i} q_{i}^{2}+b_{i} e_{i}^{2}}{\left(P_{i}-c_{I i}-c_{H i}\right) S_{I i}-g_{i}} \\
\pi_{H i 2}=\left(w_{i}-c_{H i}\right) S_{I i}+a_{i} q_{i}{ }^{2}-b_{i} e_{i}{ }^{2}
\end{gathered}
$$

To get the first order condition for the $e$, we use the Lagrange multiplier method

$$
\begin{gathered}
\frac{\partial L_{I i}}{\partial e_{i}}=\left(P_{i}-c_{I i}-w_{i}\right) \frac{\partial S_{I i}}{\partial e_{i}}+b_{i}+\lambda \frac{\partial \mathrm{g}_{i}}{\partial i_{i}}=0 \\
\frac{\partial L_{H i}}{\partial q_{i}}=\left(P_{i}-c_{H i}\right) \frac{\partial S_{H i}}{\partial q_{i}}+\left(w_{i}-c_{H i}\right) \frac{\partial S_{I i}}{\partial e_{i}}+a_{i}=0
\end{gathered}
$$

By comparing Conditions (19), (20) and (24), we can find that $\left(e_{i}^{*}=e_{i}^{o}, q_{i}^{*}=q_{i}^{o}\right)$ is the only optimal solution to Condition (24). Like in the first setting, this contract can arbitrarily allocate the profits 
between the OTA and a specific hotel. Therefore, there is no difference regardless of which side offers this contract.

We illustrate the contract with a numerical example. Suppose that besides the original hotel in the first setting, there is another hotel considering signing a new contract with the OTA. Therefore, this is a two suppliers/one retailer problem. The second hotel's demand also follows a normal distribution; thus, the expected direct customer volume of the first and the second hotels will be

$$
\begin{aligned}
& S_{H 1}\left(q_{1}, e_{1}\right)=\left(Q_{1}-q_{1}\right)-\int_{0}^{Q_{1}-q_{1}} \frac{1}{2}\left[1+\operatorname{erf}\left(\frac{z-u_{H 1}}{\sigma_{H 1} \sqrt{2}}\right)\right] d z \\
& S_{H 2}\left(q_{2}, e_{2}\right)=\left(Q_{2}-q_{2}\right)-\int_{0}^{Q_{2}-q_{2}} \frac{1}{2}\left[1+\operatorname{erf}\left(\frac{z-u_{H 2}}{\sigma_{H 2} \sqrt{2}}\right)\right] d z
\end{aligned}
$$

The expected customer volume faced by the OTA will be

$$
\begin{gathered}
=S_{I 1}+S_{I 2} \\
=q_{1}-\int_{0}^{q_{1}} \frac{1}{2}\left[1+\operatorname{erf}\left(\frac{y-u_{I 1}}{\sigma_{I 1} \sqrt{2}}\right)\right] d y+q_{2}-\int_{0}^{q_{2}} \frac{1}{2}\left[1+\operatorname{erf}\left(\frac{y-u_{I 2}}{\sigma_{I 2} \sqrt{2}}\right)\right] d y
\end{gathered}
$$

We further assume the following.

$$
\begin{gathered}
\mu_{I 1}=100+10 e_{1}, \sigma_{I 1}=100, \mu_{H 1}=150+5 e_{1}, \sigma_{H 1}=150, P=200, c_{I 1}=10, c_{H 1} \\
=50, Q_{1}=200, \mathrm{~g}_{1}=10 \times e_{1}{ }^{2} \\
\mu_{I 2}=120+15 e_{2}, \sigma_{I 2}=80, \mu_{H 2}=120+4 e_{2}, \sigma_{H 2}=100, P=180, c_{I 2}=8, c_{H 2} \\
=40, Q_{2}=150, \mathrm{~g}_{2}=12 \times e_{2}{ }^{2}
\end{gathered}
$$

When the constraint on the marketing budget is loose, there will be no split effort problem, and thus these two hotels independently cooperate with the OTA, just like in the first setting. In this situation, we calculate that $M$ should be larger than 2291.79.

More realistically, we constrain $M=1800$. The optimal decision is then $e_{1}^{o}=11.54, e_{2}^{o}=6.25$, $q_{1}^{o}=113.264, q_{2}^{o}=109.524$, and the optimal profit of the whole system is $\pi^{o}=43,252.9$.

Under simple wholesale contracts, using backward deduction, we can find a dominant Nash equilibrium result.

$e_{1}^{*}=12.24, e_{2}^{*}=5.02, q_{1}^{*}=61.21, q_{2}^{*}=53.62, w_{1}^{*}=158.6$, and $w_{2}^{*}=137.4$.

The profits of the OTA, hotel 1 , and hotel 2 , will respectively be

$\pi_{I}^{*}=1885.1, \pi_{H 1}^{*}=23,509.4$, and $\pi_{H 2}^{*}=16,075.2$.

Therefore, the total profit of this system will be

$\pi^{*}=41,469.7$.

Here, the loss due to the double-marginalization effect is approximately $5 \%$.

If they use an incentive shifting contract, as in the first setting, the hotels and the OTA will get continuously changeable profits based on the comparative size of their respective negotiation power, while the system profit will remain at the first-best solution:

$e_{1}^{n}=e_{1}^{o}=11.54, e_{2}^{n}=e_{2}^{o}=6.25, q_{1}^{n}=q_{1}^{o}=113.264$, and $q_{2}^{n}=q_{2}^{o}=109.254$.

We summarize the numerical results in Table 3. In keeping with what we have found in the one-to-one model, as the OTA's negotiation power $(\varphi)$ increase, the wholesale price $(w)$, the contract parameter $b$ and the hotels' profits will decrease but the contract parameter $a$ and the OTA's profits will increase. Although the two hotels both achieve maximal profits when $>\varphi_{1}=0.05$ and $\varphi_{2}=0.05$, the OTA makes the least level of profits, which makes the OTA willing to improve its own negotiation power. Therefore, when $\varphi_{1}=0.05$ and $\varphi_{2}=0.1$, all three firms will definitely be better off. 
Table 3. Numerical result in the one OTA and two suppliers setting

\begin{tabular}{ccccccccccc}
\hline$\varphi_{1}$ & $\varphi_{2}$ & $w_{1}$ & $w_{2}$ & $a_{1}$ & $a_{2}$ & $b_{1}$ & $b_{2}$ & $\pi_{I}$ & $\pi_{H 1}$ & $\pi_{H 2}$ \\
\hline 0.05 & 0.05 & 183.144 & 163.528 & 0.026 & 0.035 & 12.081 & 17.053 & 1350.56 & 23,999 & $17,903.3$ \\
\hline 0.05 & 0.1 & 183.144 & 150.567 & 0.026 & 0.088 & 12.081 & 15.613 & 2026.7 & 23,999 & $17,227.2$ \\
\hline 0.1 & 0.1 & 169.641 & 150.567 & 0.076 & 0.088 & 11.274 & 15.613 & 2700.87 & $23,324.8$ & $17,227.2$ \\
\hline 0.5 & 0.5 & 61.618 & 46.887 & 0.480 & 0.516 & 4.819 & 4.099 & $13,503.4$ & $17,931.5$ & $11,818.1$ \\
\hline
\end{tabular}

\section{Conclusions}

In this paper, we study two typical hospitality supply chains: one is formed by an OTA (as a sale channel) and the second one is a more realistic setting, where the OTA sells on behalf of multiple hotels. As in the current practice, hotels determine the upper bound of how many rooms should be allocated to the OTA to sell, and the OTA then makes decisions on how much effort it should exert to market each hotel on its website (most commonly done through page position and rank).

We have theoretically shown that using the current practice (through a commission model or merchant model), the double-marginalization effect exists resulting in suboptimal system-wide decisions. We discuss the inappropriateness of many current coordination contracts for the hospitality supply chain. To overcome this problem that arises from the commission model and merchant model, we develop a new type of contract to coordinate the relationships between the OTA and each individual hotel. We prove that this incentive shifting contract can thoroughly coordinate 1-1 and 1-n hospitality supply chains, which means that this contract can result in the Nash equilibrium of the game between all participants being equal to the first-best result and can arbitrarily split the entire profits (as a function of the OTA's and the specific hotel's negotiation power). As each part will benefit from this incentive shifting contract, they will adopt it regardless of their negotiation powers.

To summarize, there are some contributing points and limitations of our study. First, this paper researches a contract that can coordinate two channels where one channel's marketing effort can boost the demand of both channels, which will theoretically contribute to filling the research gap. Second, we conduct our research by combining hotel revenue management, such as the room allocation, with supply chain coordination (through contracts with OTAs), which has never previously been studied. Third, we further develop the model by extending it from a one-to-one setting to a multi-hotel and one OTA setting, where the OTA can allocate its marketing effort (website space or page rank) to influence the customers demand for these hotels' rooms. Last but not least, the demand function in our paper is in a general form and can very easily be extended to other settings beyond our travel related focus. Extending our model to a multi-OTA and one hotel setting or a multi-to-multi setting will be one of the future research directions for us. Furthermore, in this paper, we assume that the hotel retail price is equal to the OTA retail price, but this assumption may fail in reality. Therefore, to be more applicable in real business, we will abandon this assumption and develop the model into a setting where the hotel retail price is not equal to the OTA retail price and where the hotel retail price will be one of the decision variables set by the hotel. Since the current study only studied the two-level supply chain of hotels and OTAs, the three-level supply chain of bilateral efforts and risk attitudes can be considered in future work to obtain a more representative model.

\section{Evidences and Results}

\subsection{Evidence of Optimal Decisions}

Assume the marketing effort has two forms to affect the demand, the demand will be $y-z(e)$ or $y+z(e)$ (Taylor, [29]; Lariviere \& Porteus, [52]). Assume $z(e)$ is non-negative, and $z^{\prime}(e)>0, z^{\prime \prime}(e) \leq 0$, which means more efforts will bring more demand, but follows the law of diminishing returns. 
i. $F(y \mid e)=F\left(\frac{y}{z(e)}\right)$, then

$$
\begin{gathered}
S_{I}(q, e)=q-\int_{0}^{q} F(y \mid e) d y=q-z(e) \int_{0}^{\frac{q}{z(e)}} F(y) d y \\
\frac{\partial^{2} S_{I}(q, e)}{\partial q^{2}}=-\frac{1}{z(e)} f\left(\frac{q}{z(e)}\right)<0 \\
\frac{\partial^{2} S_{I}(q, e)}{\partial e^{2}}=\frac{q z^{\prime \prime}(e)}{z(e)} F\left(\frac{q}{z(e)}\right)-\frac{q^{2} z^{\prime 2}(e)}{z^{3}(e)} f\left(\frac{q}{z(e)}\right)-z^{\prime \prime}(e) \int_{0}^{\frac{q}{z(e)}} F(y) d y<0 \\
\frac{\partial^{2} S_{I}}{\partial q \partial e}=\frac{q z^{\prime}(e)}{z^{2}(e)} f\left(\frac{q}{z(e)}\right)>0 \\
\frac{\partial^{2} S_{I}}{\partial q^{2}} \frac{\partial^{2} S_{I}}{\partial e^{2}}-\left(\frac{\partial^{2} S_{I}}{\partial q \partial e}\right)^{2}=\frac{z^{\prime \prime}(e)}{z(e)} f\left(\frac{q}{z(e)}\right)\left[\int_{0}^{\frac{q}{z(e)}} F(y) d y-\frac{q}{z(e)} F\left(\frac{q}{z(e)}\right)\right] \geq 0
\end{gathered}
$$

ii. $F(y \mid e)=F(y-z(e))$, then

$$
\begin{gathered}
S_{I}(q, e)=q-\int_{0}^{q-z(e)} F(y) d y \\
\frac{\partial^{2} S_{I}(q, e)}{\partial q^{2}}=-f(q-z(e))<0 \\
\frac{\partial^{2} S_{I}(q, e)}{\partial e^{2}}=z^{\prime \prime}(e) F(q-z(e))-z^{\prime 2}(e) f(q-z(e))<0 \\
\frac{\partial^{2} S_{I}}{\partial q \partial e}=z^{\prime}(e) f(q-z(e))>0 \\
\frac{\partial^{2} S_{I}}{\partial q^{2}} \frac{\partial^{2} S_{I}}{\partial e^{2}}-\left(\frac{\partial^{2} S_{I}}{\partial q \partial e}\right)^{2}=-z^{\prime \prime}(e) F(q-z(e)) f(q-z(e)) \geq 0
\end{gathered}
$$

Similarly, $\frac{\partial^{2} \mathrm{~S}_{\mathrm{H}}}{\partial \mathrm{e}^{2}}<0, \frac{\partial^{2} \mathrm{~S}_{\mathrm{H}}}{\partial \mathrm{q}^{2}}<0, \frac{\partial^{2} \mathrm{~S}_{\mathrm{H}}}{\partial \mathrm{q} \partial \mathrm{e}}<0, \frac{\partial^{2} \mathrm{~S}_{\mathrm{H}}}{\partial \mathrm{q}^{2}} \frac{\partial^{2} \mathrm{~S}_{\mathrm{H}}}{\partial \mathrm{e}^{2}}-\left(\frac{\partial^{2} \mathrm{~S}_{\mathrm{H}}}{\partial \mathrm{q} \partial \mathrm{e}}\right)^{2} \geq 0$, and we assumed that $\frac{\partial^{2} \mathrm{~g}}{\partial \mathrm{e}^{2}}>0$, thus,

$$
\begin{aligned}
& \mathrm{H}(\Pi)=\frac{\partial^{2} \Pi}{\partial \mathrm{q}^{2}} * \quad \frac{\partial^{2} \Pi}{\partial \mathrm{e}^{2}}-\left(\frac{\partial^{2} \Pi}{\partial \mathrm{q} \partial \mathrm{e}}\right)^{2} \\
& =\left(\mathrm{P}-\mathrm{C}_{\mathrm{I}}-\mathrm{C}_{\mathrm{H}}\right)^{2}\left[\frac{\partial^{2} \mathrm{~S}_{\mathrm{I}}}{\partial \mathrm{q}^{2}} \frac{\partial^{2} \mathrm{~S}_{\mathrm{I}}}{\partial \mathrm{e}^{2}}-\left(\frac{\partial^{2} \mathrm{~S}_{\mathrm{I}}}{\partial \mathrm{q} \partial \mathrm{e}}\right)^{2}\right] \\
& +\left(\mathrm{P}-\mathrm{C}_{\mathrm{H}}\right)^{2}\left[\frac{\partial^{2} \mathrm{~S}_{\mathrm{H}}}{\partial \mathrm{q}^{2}} \frac{\partial^{2} \mathrm{~S}_{\mathrm{H}}}{\partial \mathrm{e}^{2}}-\left(\frac{\partial^{2} \mathrm{~S}_{\mathrm{H}}}{\partial \mathrm{q} \partial \mathrm{e}}\right)^{2}\right] \\
& +\left(\mathrm{P}-\mathrm{c}_{\mathrm{I}}-\mathrm{c}_{\mathrm{H}}\right)\left(\mathrm{P}-\mathrm{c}_{\mathrm{H}}\right)\left[\frac{\partial^{2} \mathrm{~S}_{\mathrm{I}}}{\partial \mathrm{q}^{2}} \frac{\partial^{2} \mathrm{~S}_{\mathrm{H}}}{\partial \mathrm{e}^{2}}+\frac{\partial^{2} \mathrm{~S}_{\mathrm{I}}}{\partial \mathrm{e}^{2}} \frac{\partial^{2} \mathrm{~S}_{\mathrm{H}}}{\partial \mathrm{q}^{2}}-2 \frac{\partial^{2} \mathrm{~S}_{\mathrm{I}}}{\partial \mathrm{q} \partial \mathrm{e}} \frac{\partial^{2} \mathrm{~S}_{\mathrm{H}}}{\partial \mathrm{q} \partial \mathrm{e}}\right] \\
& -\left(\mathrm{P}-\mathrm{c}_{\mathrm{I}}-\mathrm{c}_{\mathrm{H}}\right) \frac{\partial^{2} \mathrm{~S}_{\mathrm{I}}}{\partial \mathrm{q}^{2}} \frac{\partial^{2} \mathrm{~g}}{\partial \mathrm{e}^{2}}-\left(\mathrm{P}-\mathrm{c}_{\mathrm{H}}\right) \frac{\partial^{2} \mathrm{~S}_{\mathrm{H}}}{\partial \mathrm{q}^{2}} \frac{\partial^{2} \mathrm{~g}}{\partial \mathrm{e}^{2}}>0
\end{aligned}
$$

The Hessian matrix as the above inequation shows, which implies that the optimization problem of the one-to-one model has optimal solutions.

\subsection{Evidence of Theorem 1}

Substitute Condition (8) into Condition (7), and deduce the first order condition of $e$ and $q$, respectively, we can get

$$
\begin{aligned}
\Pi_{\mathrm{I}}=\phi\left[\left(\mathrm{P}-\mathrm{c}_{\mathrm{H}}\right) \mathrm{S}_{\mathrm{H}}+\left(\mathrm{P}-\mathrm{c}_{\mathrm{I}}-\mathrm{c}_{\mathrm{H}}\right) \mathrm{S}_{\mathrm{I}}-\mathrm{g}\right] & =\phi \Pi \\
\Pi_{\mathrm{H}}=(1-\phi)\left[\left(\mathrm{P}-\mathrm{c}_{\mathrm{H}}\right) \mathrm{S}_{\mathrm{H}}+\left(\mathrm{P}-\mathrm{c}_{\mathrm{I}}-\mathrm{c}_{\mathrm{H}}\right) \mathrm{S}_{\mathrm{I}}-\mathrm{g}\right] & =(1-\phi) \Pi
\end{aligned}
$$

Through the setting of parameter $\phi$, profits can be arbitrarily distributed between hotel and OTA. That is, reverse profit sharing contracts can coordinate the hospitality supply chain. 


\subsection{Evidence of Theorem 2}

Substitute $w, a, b$ into $\Pi_{\mathrm{I}}, \Pi_{\mathrm{H}}$, and deduce the first order condition of $e$ and $q$, respectively, we can find

$$
\begin{gathered}
\frac{\partial \Pi_{I}}{\partial e}-\frac{\partial \Pi}{\partial e}=\left(w-c_{H}\right)\left(\left.\frac{\partial S_{I}}{\partial e}\right|_{e^{0}, q^{0}}-\frac{\partial S_{I}}{\partial e}\right)+\left(P-c_{H}\right)\left(\left.\frac{\partial S_{H}}{\partial e}\right|_{e^{0}, q^{0}}-\frac{\partial S_{H}}{\partial e}\right) \\
\frac{\partial \Pi_{H}}{\partial q}-\frac{\partial \Pi}{\partial q}=\left(P-c_{I}-w\right)\left(\frac{\partial S_{I}}{\partial q}-\frac{\partial S_{I}}{\partial q} \mid e^{0}, q^{0}\right)
\end{gathered}
$$

which means

$$
\begin{aligned}
& \frac{\partial \Pi_{\mathrm{I}}}{\partial e}-\frac{\partial \Pi}{\partial e}=\frac{\partial \Pi}{\partial e}=\frac{\partial \Pi_{\mathrm{I}}}{\partial e}=\frac{\partial \Pi_{\mathrm{H}}}{\partial e}=\left.0\right|_{e^{0}, q^{0}} \\
& \frac{\partial \Pi_{\mathrm{H}}}{\partial q}-\frac{\partial \Pi}{\partial q}=\frac{\partial \Pi}{\partial q}=\frac{\partial \Pi_{\mathrm{H}}}{\partial q}=\frac{\partial \Pi_{\mathrm{I}}}{\partial q}=\left.0\right|_{e^{0}, q^{0}}
\end{aligned}
$$

Thus, the OTA and the hotel will rationally set their respective optimal decisions $e^{*}$ and $q^{*}$ equal to the first-best decision pair $e^{0}, q^{0}$ in a centralized system (incentive compatibility constraint). Furthermore, because this contract can arbitrarily allocate the profits, there is no difference regardless of which side offers this contract. This is referred to as a perfectly coordinated supply chain.

Author Contributions: J.D. and Q.G.: Both of them did the conceptualization the idea of study design, a writeup of the original draft and methodology. Q.J. and P.Z.: Both did the review, editing, formal data analysis, and validation. C.K.A.: undertook the survey, review and editing. All authors have read and agreed to the published version of the manuscript.

Funding: This work was supported by National Natural Science Foundation of China: [Grant Number 71661006]; Fundamental Research Funds for the Central Universities: [Grant Number PA2019GDQT0005].

Conflicts of Interest: The authors declare no conflicts of interest

\section{References}

1. Stangl, B.; Inversini, A.; Schegg, R. Hotels' dependency on online intermediaries and their chosen distribution channel portfolios: Three country insights. Int. J. Hosp. Manag. 2016, 52, 87-96. [CrossRef]

2. Raguseo, E.; Neirotti, P.; Paolucci, E. How small hotels can drive value their way in infomediation. the case of 'italian hotels vs. otas and tripadvisor'. Inf. Manag. 2016, 54, 745-756. [CrossRef]

3. Guo, X.; Zheng, X.; Ling, L. Online coopetition between hotels and online travel agencies: From the perspective of cash back after stay. Tour. Manag. Perspect. 2014, 12, 104-112. [CrossRef]

4. Hui, S.; Law, R.; Ye, Q. An analysis of the best online rates for hotels in China. J. Hosp. Mark. Manag. 2009, 18, 829-844. [CrossRef]

5. Law, R.; Guillet, B.; Leung, R. An Analysis of The Lowest Fares and Shortest Durations for Air-Tickets on Travel Agency Websites. J. Travel Tour. Mark. 2010, 27, 635-644. [CrossRef]

6. Anderson, C.K. The Billboard Effect: Online Travel Agent Impact on Non-OTA Reservation. Cornell Cent. Hosp. Res. Rep. 2009, 9, 5-9.

7. Anderson, C.K. Search, OTAs, and Online Booking: An Expanded Analysis of the Billboard Effect. Cornell Cent. Hosp. Res. Rep. 2011, 11, 4-8.

8. Ling, L.; Dong, Y.; Guo, X.; Liang, L. Availability management of hotel rooms under cooperation with online travel agencies. Int. J. Hosp. Manag. 2015, 50, 145-152. [CrossRef]

9. Chan, I.C.C.; Lam, L.W.; Chow, C.W.; Fong, L.H.N.; Law, R. The effect of online reviews on hotel booking intention: The role of reader-reviewer similarity. Int. J. Hosp. Manag. 2017, 66, 54-65. [CrossRef]

10. Chang, Y.W.; Hsu, P.Y.; Lan, Y.C. Cooperation and competition between online travel agencies and hotels. Tour. Manag. 2019, 71, 187-196. [CrossRef]

11. Spengler, J.J. Vertical integration and antitrust policy. J. Political Econ. 1950, 58, 347-352. [CrossRef]

12. Tirole, J. The Theory of Industrial Organization; MIT Press: Cambridge, MA, USA, 1988.

13. Cachon, G.P. Supply chain coordination with contracts. In Handbooks in Operations Research and Management Science: Supply Chain Management; Elsevier: Amsterdam, The Netherlands, 2003; Volume 11, pp. 227-339.

14. Hsieh, C.; Chang, Y.; Wu, C. Competitive pricing and ordering decisions in a multiple-channel supply chain. Int. J. Prod. Econ. 2014, 154, 156-165. [CrossRef]

15. Dong, J.; Wu, D. Two-period pricing and quick response with strategic customers. Int. J. Prod. Econ. 2019, 215, 165-173. [CrossRef] 
16. Ghoreishi, M.; Mirzazadeh, A.; Weber, G.W. Optimal pricing and ordering policy for non-instantaneous deteriorating items under inflation and customer returns. Optimization 2014, 63, 1785-1804. [CrossRef]

17. Dong, J.; Jiang, L.; Lu, W.; Guo, Q. Closed-loop supply chain models with product remanufacturing under random demand. Optimization 2019. [CrossRef]

18. Tantiwattanakul, P.; Dumrongsiri, A. Supply chain coordination using wholesale prices with multiple products, multiple periods, and multiple retailers: Bi-level optimization approach. Comput. Ind. Eng. 2019, 191, 391-407. [CrossRef]

19. Wu, G.; Kong, Q.; Shi, J.; Karimi, H.; Zhang, W. Information Sharing and Channel Construction of Supply Chain under Asymmetric Demand Information. J. Appl. Math. 2014, 3, 1-8. [CrossRef]

20. Sher, M.M.; Kim, S.L.; Banerjee, A.; Paz, M.T. A supply chain coordination mechanism for common items subject to failure in the electronics, defense, and medical industries. Int. J. Prod. Econ. 2018, 203, 164-173. [CrossRef]

21. Henschel, U.K. Hotel Management, 3nd ed.; Oldenbourg: Munich, Germany, 2008.

22. Pasternack, B.A. Optimal pricing and return policies for perishable commodities. Mark. Sci. 1985, 4, $166-176$. [CrossRef]

23. Dana, J.D., Jr.; Spier, K.E. Revenue sharing and vertical control in the video rental industry. J. Ind. Econ. 2003, 49, 223-245. [CrossRef]

24. Tsay, A.A.; Lovejoy, W.S. Quantity Flexibility Contracts and Supply Chain Performance. Manuf. Serv. Oper. Manag. 1999, 1, 89-111. [CrossRef]

25. Shi, J.; Zhang, G.; Lai, K. Optimal ordering and pricing policy with supplier quantity discounts and price-dependent stochastic demand. Optimization 2011, 61, 151-162. [CrossRef]

26. Zhao, H.; Lin, B.; Mao, W.; Ye, Y. Differential Game Analyses of Logistics Service Supply Chain Coordination by Cost Sharing Contract. J. Appl. Math. 2014, 3, 1-10. [CrossRef]

27. Xu, G.; Dan, B.; Zhang, X.; Liu, C. Coordinating a dual-channel supply chain with risk-averse under a two-way revenue sharing contract. Int. J. Prod. Econ. 2014, 147, 171-179. [CrossRef]

28. Tsao, Y.C.; Sheen, G.J. Effects of promotion cost sharing policy with the sales learning curve on supply chain coordination. Comput. Oper. Res. 2012, 39, 1872-1878. [CrossRef]

29. Taylor, T.A. Supply chain coordination under channel rebates with sales effort effects. Manag. Sci. 2002, 48, 992-1007. [CrossRef]

30. Scott, N.; Green, C.; Fairley, S. Investigation of the use of eye tracking to examine tourism advertising effectiveness. Curr. Issues Tour. 2015, 19, 634-642. [CrossRef]

31. Jurado, F.; Leiva, F.; Correia, M.; Sousa, C.M.; Ramos, C.M.; Faísca, L. Visual attention to the main image of a hotel website based on its position, type of navigation and belonging to Millennial generation: An eye tracking study. J. Retail. Consum. Serv. 2019, 52, 101906. [CrossRef]

32. Leiva, F.; Mendez, J.; Carmona, D. Measuring advertising effectiveness in travel 2.0 websites through eye-tracking technology. Physiol. Behav. 2018, 200, 83-95. [CrossRef]

33. Yan, R.; Pei, Z. Retail services and firm profit in a dual-channel market. J. Retail. Consum. Serv. 2009, 16, 306-314. [CrossRef]

34. Dan, B.; Xu, G.; Liu, C. Pricing policies in a dual-channel supply chain with retail services. Int. J. Prod. Econ. 2012, 139, 312-320. [CrossRef]

35. Routroy, S.; Dixit, M.; Kumar, C.V.S. Achieving Supply Chain Coordination through Lot Size Based Discount. In Proceedings of the 4th International Conference on Materials Processing and Characterization 2015, Andhra Pradesh, India, 14-15 February 2015; Volume 2, pp. 2433-2442.

36. Krishnan, H.; Kapuscinski, R.; Butz, D. Coordinating con-tracts for decentralized supply chains with retailer promotional effort. Manag. Sci. 2001, 50, 48-63. [CrossRef]

37. Ma, P.; Wang, H.; Shang, J. Contract design for two-stage supply chain coordination: Integrating manufacturer-quality and retailer-marketing efforts. Int. J. Prod. Econ. 2013, 146, 745-755. [CrossRef]

38. Chen, J.; Zhang, H.; Sun, Y. Implementing coordination contracts in a manufacturer Stackelberg dual-channel supply chain. Omega 2012, 40, 571-583. [CrossRef]

39. Cai, J.; Hu, X.; Tadikamalla, P.; Shang, J. Flexible contract design for VMI supply chain with service-sensitive demand: Revenue-sharing and supplier subsidy. Eur. J. Oper. Res. 2017, 261, 143-153. [CrossRef]

40. Zhao, D.; Chen, M.; Gong, Y. Strategic information sharing under revenue-sharing contract: Explicit vs. tacit collusion in retailers. Comput. Ind. Eng. 2019, 131, 99-114. [CrossRef] 
41. Cai, G. Channel Selection and Coordination in Dual-Channel Supply Chains. J. Retail. 2010, 86, 22-36. [CrossRef]

42. Panja, S.; Mondal, S.K. Exploring a two-layer green supply chain game theoretic model with credit linked demand and mark-up under revenue sharing contract. J. Clean. Prod. 2019, 250, 119491. [CrossRef]

43. Wang, S.Y.; Choi, S.H. Pareto-efficient coordination of the contract-based MTO supply chain under flexible cap-and-trade emission constraint. J. Clean. Prod. 2019, 250, 119571. [CrossRef]

44. Zhao, J.; Zhou, Y.W.; Cao, Z.H.; Min, J. The shelf space and pricing strategies for a retailer-dominated supply chain with consignment-based revenue sharing contracts. Eur. J. Oper. Res. 2019, 280, 926-939. [CrossRef]

45. Ryan, J.; Sun, D.; Zhao, X. Coordinating a Supply Chain with a Manufacturer-Owned Online Channel: A Dual Channel Model Under Price Competition. IEEE Trans. Eng. Manag. 2013, 60, 247-259. [CrossRef]

46. Guo, X.; He, L. Tourism supply-chain coordination: The cooperation between tourism hotel and tour operator. Tour. Econ. 2012, 18, 1361-1376. [CrossRef]

47. Hua, Q.; Wei, Y.; Xia, Y. Revenue management for a supply chain with two streams of customers. Eur. J. Oper. Res. 2010, 200, 582-598. [CrossRef]

48. Guo, X.; Ling, L.; Dong, Y.; Liang, L. Cooperation contract in tourism supply chains: The optimal pricing strategy of hotels for cooperative third-party strategic websites. Ann. Tour. Res. 2013, 41, 20-41. [CrossRef]

49. Ling, L.; Guo, X.; Yang, C. Opening the online marketplace: An examination of hotel pricing and travel agency on-line distribution of rooms. Tour. Manag. 2014, 45, 234-243. [CrossRef]

50. Yang, Y.; Leung, X. A better last-minute hotel deal via app? Cross-channel price disparities between Hotel Tonight and OTAs. Tour. Manag. 2018, 68, 198-209. [CrossRef]

51. Katerina, T.; Nicolaos, P. Diagnosing user perception and acceptance using eye tracking in web-based end-user development. Comput. Hum. Behav. 2017, 72, $23-37$.

52. Lariviere, M.; Porteus, E. Selling to the newsvendor: An analysis of price-only contracts. Manuf. Serv. Oper. Manag. 2001, 3, 293-305. [CrossRef]

(C) 2020 by the authors. Licensee MDPI, Basel, Switzerland. This article is an open access article distributed under the terms and conditions of the Creative Commons Attribution (CC BY) license (http://creativecommons.org/licenses/by/4.0/). 